\title{
La captura del Estado peruano por el narcotráfico: el caso de los "cuello blanco del puerto"
}

The Capture of the Peruvian State by Drug Trafficking: the Case of «the White Collars of the Port»

\section{LAURA ZÚÑIGA RODRÍGUEZ}

\author{
Universidad de Salamanca, España
}

\begin{abstract}
RESUMEN: Desde los años ochenta el Perú es una pieza clave en el escenario internacional del tráfico de drogas. Segundo productor de cocaína del mundo y uno de los países donde se cultiva el principal insumo, la hoja de coca, el puerto de El Callao, siendo uno de los principales puertos de América Latina por su volumen, se presume que es desde donde salen importantes cargas de esa droga. La interceptación de las comunicaciones en 2018 para investigar el crimen organizado violento que se desarrollaba en esa Provincia, desveló una red de jueces, fiscales, congresistas, empresarios, que colaboraban con los narcotraficantes favoreciéndoles con la impunidad. No es el primer intento de captura del Estado peruano por el narcotráfico. En la década de los noventa, el gobierno de FujimoriMontesinos, utilizó el dinero del narcotráfico - entre otros- para sobornar a las más altas autoridades del país: jefes militares, Corte Suprema, Fiscal de la Nación, medios de comunicación, empresarios, todos afines al gobierno. Los "narcoindultos" del segundo gobierno de Alan García son otro síntoma de la gravedad de la colaboración de autoridades de las más altas esferas del Estado con los poderosos narcotraficantes. Se pone en evidencia la "doble moral" de la Política Criminal peruana contra el tráfico internacional de drogas, fuerte para los débiles y débil para los fuertes: penas altas para los pequeños traficantes e impunidad para los que se encuentran en el vértice de las organizaciones criminales. Además, resulta preocupante la enorme capacidad corruptora del dinero proveniente del narcotráfico (blanqueo de dinero) para capturar miembros de los poderes del Estado: Ejecutivo, Legislativo y Judicial. El caso "cuellos blanco del puerto" es una muestra empírica de la intersección de la corrupción judicial -y sus adláteres- dentro del Estado peruano y las organizaciones del crimen organizado. Para conjurar estas alianzas, es preciso poner el acento en la punición de los delincuentes de cuello blanco del narcotráfico y sus colaboradores: abogados, jueces, fiscales, etc., que utilizan su profesión como tapadera para enriquecerse personalmente, en desmedro del bien común.
\end{abstract}

PALABRAS Clave: Tráfico internacional de drogas, Corrupción judicial, Blanqueo de dinero, Delincuente de cuello blanco, Impunidad.

ABSTRACT: Since the 1980s, Peru has been a key player in the international drug trafficking scenario. The second largest producer of cocaine in the world and one of the countries where the main input, the coca leaf, is grown, the port of El Callao, being one 
of the main ports in Latin America due to its volume, is presumed to be where important cargoes of this drug leave from. The interception of communications in 2018 to investigate the violent organized crime that was taking place in that province revealed a network of judges, prosecutors, congressmen, and businessmen who were collaborating with drug traffickers, favoring them with impunity. This is not the first attempt to capture the Peruvian State for drug trafficking. In the 1990s, the government of FujimoriMontesinos used drug trafficking money -among others- to bribe the country's highest authorities: military chiefs, the Supreme Court, the Attorney General, the media, and businessmen, all of whom were close to the government. The "narco-indulgence" of Alan García's second administration is another symptom of the seriousness of the collaboration of authorities from the highest spheres of the State with the powerful drug traffickers. The "double standard" of the Peruvian Criminal Policy against international drug trafficking is made evident, strong for the weak and weak for the strong: high penalties for smallscale traffickers and impunity for those at the apex of the criminal organizations. In addition, the enormous corrupting capacity of money from drug trafficking (money laundering) to capture members of the powers of the State: Executive, Legislative and Judicial, is of concern. The "case of the white collars of the port" is an empirical example of the intersection of judicial corruption -and its minions- within the Peruvian State and the organized crime criminal organizations. In order to conjure up these alliances, it is necessary to emphasize the punishment against the white-collar criminals of drug trafficking and their collaborators: lawyers, judges, prosecutors, etc., who use their profession as a cover to enrich themselves personally to the detriment of the common good.

KEYWORDS: International drug trafficking, Judicial corruption, Money laundering, White collar crime, Impunity.

Recibido: 9 de noviembre de 2020. Aceptado : 20 de noviembre de 2020.

Revista de Estudios en Seguridad Internacional, Vol. 6, No. 2, (2020), pp. 175-191. http://www.seguridadinternacional.es/revista/

ISSN: 2444-6157. DOI: http://dx.doi.org/10.18847/1.12.10 


\section{INTRODUCCIÓN: EL NARCOTRÁFICO COMO DELITO TRANSNACIONAL}

El narcotráfico es una de las industrias más rentables del mundo. Su capacidad para generar grandes ganancias rápidamente le convierte en un fenómeno criminal con una dimensión corruptora sin precedentes. Los beneficios acumulados (que deben ser reciclados, es decir, introducidos a la economía legal) sirven de anzuelo para las autoridades de los Estados que se ven fácilmente tentados por los ofrecimientos de los narcotraficantes, incomparables con los bajos sueldos que ganan como funcionarios públicos. Se trata, por tanto, de un negocio ilegal sumamente exitoso: mientras crecen los beneficios de los infractores, los Estados -más en épocas de recortes- se ven limitados en sus medios materiales y personales para la persecución penal. Es, pues, un combate desigual en armas, donde se mide indudablemente la fortaleza de las instituciones estatales y de su sociedad.

Además, el narcotráfico es un fenómeno criminal que ofrece todas las dificultades para su persecución penal caracterizadas de la criminalidad organizada: se comete por medio de organizaciones criminales (de diversos tipos y magnitudes), de carácter transnacional, utiliza negocios lícitos, uso de la violencia, búsqueda de la impunidad, etc. Estamos ante la principal expresión de la criminalidad organizada transnacional, la cual, al lado de la trata y tráfico de personas, genera las mayores ganancias del crimen global. Por tanto, uno de sus principales problemas es su carácter transnacional, esto es, que se aprovecha de la libertad de movimientos, los avances de las telecomunicaciones, las debilidades de los Estados, la pobreza y la miseria de sus Sociedades, para medrar y expandirse por todo el orbe con la utilización de sus incalculables medios económicos. Se trata de un negocio a escala internacional, donde existen repartos de territorios, funciones, mercados, suministradores de bienes y servicios, etc., muy similarmente a la empresa-red de la economía formal. Con la ventaja de que esta industria supera todas las fronteras y las leyes de los Estados nacionales, los principios de los Estados democráticos de Derecho $\mathrm{y}$, por supuesto, no paga impuestos.

Por tanto, la capacidad de seguir creciendo y conseguir escala a nivel global es tremenda. No en vano, las organizaciones criminales de carácter internacional son considerados "actores no estatales" en el escenario mundial multipolar. Efectivamente, terminada la Guerra Fría y al albor de la desregulación financiera que facilita el reciclaje de las ganancias obtenidas, algunas organizaciones criminales internacionales, especialmente las dedicadas al narcotráfico internacional, han conseguido una estructuración compleja, mimetizadas en el tejido social, que las convierte en "nuevos poderes" con dominio de territorio y mercado, con capacidad de poner en jaque la seguridad de algunos Estados nacionales, últimamente muy mermados por el modelo liberal, según el cual han externalizado buena parte de los costos de sus aparatos.

Son muchas las ventajas competitivas que ofrecen las organizaciones criminales internacionales del narcotráfico sobre los Estados nacionales, que explican su exitoso desarrollo en las últimas tres décadas. En este trabajo me centraré en el análisis de aquellas que constituyen las más relevantes del caso peruano, que expresan el caldo de cultivo del narcotráfico en este país, su crecimiento exponencial y su pretendida captura del Estado.

\section{El NARCOTRÁFICO EN EL PERÚ}

No cabe duda que el Perú juega un papel fundamental en el tablero del narcotráfico internacional. Considerado segundo productor mundial de cocaína, seguido de Colombia, 
ocupa un puesto importante y clave en la red de las organizaciones criminales dedicadas a la producción y comercialización de las drogas. Su posición central de cara al Océano Pacífico le otorga un puesto privilegiado para enviar "cargas" importantes a cualquier parte del mundo, especialmente por vía marítima, principal medio de transporte de la cocaína. Así, no solo es el país desde el que se extrae el principal insumo, la hoja de coca y se produce y comercializa el clorhidrato de cocaína es, además, lugar de tránsito de las sofisticadas redes de los traficantes de los cárteles del propio país, México y Colombia. Desde Perú salen cargamentos de drogas hacia Europa, Este de Asia, México, El Caribe y otros países latinoamericanos (AMERIPOL, 2013: 116).

Por otro lado, el Perú sigue siendo, conjuntamente con Colombia y Bolivia los principales productores de hoja de coca, elemento básico para la elaboración de la cocaína que se vende en todo el mundo. ${ }^{1}$ Se dice que es el clima, la tierra, el cultivo ancestral de la hoja de coca en dichos países lo que hace prácticamente monopólico el cultivo de la misma, lo cual ha generado no pocos problemas en las sociedades colombiana, boliviana y peruana. En efecto, corrupción, proliferación de una economía informal, distorsiones en los tipos de cambio, aumento del consumo de drogas, violencia, incluso narcoterrorismo, por citar los efectos más evidentes. Pero además de los perjuicios generados a las personas encarceladas y sus familias, a los consumidores de drogas, puede observarse últimamente también el daño que está generando al medio ambiente el cultivo de hoja de coca. La Política Criminal auspiciada por Naciones Unidas desde 1998 de desarrollar cultivos alternativos para finalmente controlar la producción de la cocaína, ha tenido resultados irregulares, difíciles de valorar dada la complejidad de la situación.

Debe recordarse que, en Perú el cultivo de la hoja de coca corresponde a una tradición ancestral. En los pueblos andinos de Perú y Bolivia existe la costumbre de "chacchar" (masticar, en quechua) las hojas de coca para tener fortaleza en las labores y soportar el frío. Además, con la hoja de coca se elaboran mates que ayudan a sobrellevar las alturas y se fabrican otros productos derivados como jarabes, pomadas, caramelos, etc. Por tanto, existe una porción de producción legal de hoja de coca. He ahí el primer problema: las autoridades tienen que controlar cuánto corresponde a la producción legal y cuánto a la producción ilegal, pudiendo saltarse muy fácilmente esa difícil línea.

La coexistencia de un mercado legal con otro ilegal complica la persecución de estos últimos, más aún si el comportamiento del tráfico ilícito de drogas, como bien recuerda la socióloga Stöckli (2016: 10) "articula sectores de producción, transformación y de comercialización como lo haría cualquier producto legal del sistema capitalista, con la gran diferencia de los altos costos de corrupción y de lavado de activos, que elevan el costo del producto final". Asimismo, el desarrollo de la producción de la hoja de coca se produce principalmente en zonas empobrecidas, en las que no existen articulaciones con los mercados más productivos del país, dejando a los agricultores a merced de los narcotraficantes. Producida una cadena de valor más rentable que gira alrededor del narcotráfico, resulta difícil la sustitución de la producción de la hoja de coca, como reclama Naciones Unidas.

Ciertamente que se ha conseguido erradicar zonas de producción de hoja de coca, proponiendo cultivos alternativos como el cacao, pero la complejidad de la problemática

\footnotetext{
${ }^{1}$ Como recuerda Naciones Unidas, 27 de febrero de 2020, "Récords de cultivo de hoja de coca, nuevos cárteles y aumento de la violencia: la droga en América Latina": "No olvidemos que América del Sur es responsable de la producción total de la hoja de coca, pasta base y clorhidrato de cocaína en todo el mundo. Toda la red y las mafias que se originan para trasladar este producto a Europa y, sobre todo a América del Norte ha corrompido a funcionarios y está implicada con la poca predisposición para combatir esta situación en sistemas corruptos" (Noticias ONU, 2020).
} 
que puede considerarse sistémica (pobreza, práctica inexistencia del Estado peruano en amplios territorios, consolidación de cadenas de valor alrededor del narcotráfico), produce rendimientos desiguales en las diferentes zonas (Manrique-López, 2015). Ello agravado con las alianzas con grupos terroristas restantes de Sendero Luminoso, localizados principalmente en la zona del VRAEM (Valle de los Ríos Apurímac, Ene y Mantaro), cuya producción representa el $43 \%$ de la hoja de coca peruana. La coalición narcotráfico / terrorismo amenaza seriamente la institucionalidad del Estado peruano, pues no son pocos los casos de gobiernos locales y regionales procesados por narcotráfico y/o corrupción. Siendo así, la estrategia de sustituir los cultivos de hojas de coca para disminuir la producción de la droga resulta muy limitada por varios motivos. Primero, porque se aprecia últimamente que con menos hoja de coca se está produciendo más clorhidrato de cocaína. Segundo, porque lo que suele suceder es que los agricultores mantienen ambos cultivos, el sustituto y el de la hoja de coca. Tercero, creada una cadena de valor vinculada al narcotráfico, es difícil sustituirla dada la rentabilidad que en ella se genera. Mientras exista un aumento de la demanda por el consumo, parece complicado erradicar la producción del principal insumo de la cocaína, la hoja de coca ${ }^{2}$.

Situados en este punto, es fácil comprender lo complejo que resulta la persecución penal con estas coordenadas sociales y la expresión del fenómeno del narcotráfico peruano con todas estas aristas que representan un enraizamiento en amplias zonas del país. Muestra de lo que ha calado en ciertas áreas económicas vinculadas al narcotráfico, son las actividades de blanqueo de dinero que se desarrollan principalmente en esos lugares atrapados por la narcoeconomía, como cooperativas y diversos actos de corrupción (IDEHPUCP, 2018).

Existen razones suficientes para caracterizar el fenómeno del narcotráfico peruano con todos los componentes que los analistas de la criminalidad organizada transnacional suelen subrayar: gran capacidad de adaptación al medio local, aprovechamiento de vacíos del Estado en cuanto a la provisión de mercado laboral y de desarrollo, ocupación de territorios donde no llegan las autoridades estatales, fácil integración en el mercado internacional. Como apunta Armao (2014: 9), la competitividad de las organizaciones criminales internacionales se basa en su capacidad para imitar y adaptar los modelos premodernos a las demandas de un mercado internacional de bienes y servicios ilícitos. Esto es, han demostrado una adaptabilidad de las relaciones económicas capitalistas en un mundo globalizado para integrar lo local y lo global de una manera eficaz, como ningún otro actor internacional (Piedrahita, 2020).

Seguidamente me ocuparé de desarrollar algunas claves que explican el particular desarrollo del narcotráfico en el caso peruano, además de las antes citadas.

\section{LA “DOBLE MORAL”: DELITOS CONSENSUADOS}

Una de las particularidades del tráfico ilícito de drogas que lo convierte en un fenómeno social tan exitoso es que se trata de un delito consensuado: es un delito en el que el victimario (vendedor de droga) y la víctima (consumidor) están de acuerdo (Chabat, 2010: 10). Ello significa que la supuesta víctima no va a denunciar a su vendedor, sino más bien

2 Un último Informe de UNODC (2020: 8) señala "El cultivo del arbusto de coca continúa a un nivel históricamente muy alto (244 200 hectáreas). La superficie dedicada al cultivo de coca permaneció estable de 2017 a 2018. Sin embargo, la fabricación mundial estimada de cocaína alcanzó una vez más un máximo histórico (1 723 toneladas) y las incautaciones mundiales aumentaron marginalmente (1 131 toneladas)". Esta aseveración corrobora los análisis de un mayor rendimiento en la producción de la cocaína desde la hoja de coca. 
lo va a encubrir. Así las cosas, el consumidor es una parte colaborativa en el delito, por lo cual se dificulta sobremanera su persecución penal. El delito se mantiene invisible ante el contubernio entre traficantes y consumidores de drogas. Es más, respecto al consumo de cocaína, una gran parte de los consumidores suelen ser personas con posiciones sociales elevadas, como políticos, empresarios, gente del espectáculo, sujetos no interesados en acabar con ese mercado. Por eso también se considera que detrás de la persecución penal hay una doble moral: simbólicamente se persigue, pero realmente hay muchos interesados en que esa persecución no sea real y efectiva.

Por tanto, estamos ante la categoría de delitos ambiguos, en los que no existe una clara conciencia social de que se trata de conductas reprochables, intolerables, delitos graves, salvo en casos de uso coactivo o abusivo que puede darse cuando se vende a jóvenes o la imponen los tratantes a sus víctimas. La sociedad suele ser tolerante con este mercado ilícito. Tan es así que el consumo de drogas está permitido en la mayoría de países. Ello es producto de una sociedad hedonista, donde no ve mal, sino todo lo contrario, la búsqueda del placer por medio de sustancias psicoactivas, incluso prohibidas. No existe reproche social en el consumo de drogas y, por tanto, poco o nada en la venta de las mismas. El aumento de la demanda de consumo de drogas que es una constante, especialmente desde el mundo desarrollado, prueba de que se trata un bien que crece en interés. En sociedades hiperactivas, donde existe exceso de información, de búsqueda de resultados inmediatos, el uso de sustancias psicoactivas se explica por sí mismo.

Como nos recuerda Torrente (2001: 75), el propio concepto de delito es ambiguo por su naturaleza moral y de construcción social. Para que un delito acabe en una definición legal y se persiga penalmente antes tiene que ser reconocido socialmente. $\mathrm{Si}$, como es el caso, la sociedad es tolerante con la práctica del consumo de drogas, se inhiben los mecanismos de control social informal y la persecución penal se convierte en un mecanismo que se aplica selectivamente, de manera desigual y simbólica, sujeta a mecanismos deleznables, como la corrupción.

Existe, pues, un discurso público, oficial sobre la lucha contra la droga y otro privado, soterrado sobre su práctica. Los traficantes y sus colaboradores lo saben, lo mismo que algunos miembros de las fuerzas del orden, que tienen pocos escrúpulos en entrar en el juego de este simbolismo. La falta de mecanismos inhibitorios, la poca o nula consciencia de estar haciendo algo malo, explican el contubernio de los traficantes con buena parte de la sociedad. Si a ello se añade que existen muchas personas beneficiarias en el mercado de la droga, la impunidad está servida.

Efectivamente, en Perú, siguiendo a Stöckil (2014: 10), "muchos actores identifican al narcotráfico como un fenómeno de "doble moral". Por un lado, el sistema de libre mercado, con su objetivo de lucro, motiva la existencia de una narcoeconomía, que permite obtener grandes cantidades de capital, asociada con la narcopolítica, que genera la producción y reproducción del capital en alianza con el crimen organizado y cuerpos paramilitares (Suárez-Salazar, 1989). Por otro lado, las acciones de lucha contra la producción y el tráfico ilícito de drogas son una forma de control social, puesto que permite al Estado controlar zonas donde su presencia es débil y hay estructuralmente un bajo monopolio de la violencia, mediante acciones represivas intermitentes (erradicación de cultivos de hoja de coca, interdicción en insumos químicos, entre otros)".

Entre este doble juego discurren dos variables importantes: la desigualdad en la persecución penal y la corrupción, ambas, por supuesto, interrelacionadas. 


\section{UNA LUCHA ORIENTADA DE MANERA DESIGUAL}

Es común pensar que, en el combate frente al tráfico de drogas, existe una selectividad penal evidente que orienta el castigo principalmente a los sectores menos favorecidos de la cadena de valor del mercado de la droga, agricultores, pequeños traficantes, "burriers", mientras que los grandes traficantes se ven continuamente liberados de las penas de prisión. Esto es, las políticas criminales punitivistas que propician penas muy duras, con tipos penales abiertos que castigan por igual toda actuación de favorecimiento del delito, se aplican con mayor frecuencia a los pequeños traficantes, sino a los propios consumidores, quedando en muchos casos fuera del alcance de la selectividad penal los grandes capos de las mafias de la droga, infringiendo claramente un principio básico del Estado de Derecho, el principio de proporcionalidad.

Según un estudio realizado por Soberón (2010: 81), en el Perú, en promedio entre el 20 y el 24 por ciento de la población penitenciaria está en la cárcel por delitos de drogas. Sólo la tercera parte de esta población, aproximadamente, tiene su situación jurídica definida, siendo la mayoría presos preventivos. Este dato nos da un reflejo insuficiente de la incidencia del narcotráfico en el Perú, porque como se ha dicho, los que suelen ser encarcelados son los pequeños traficantes, quedando fuera de estos índices los grandes capos de las organizaciones de narcotraficantes.

Esta ha sido una constante, lamentablemente, en América Latina. Gracias al discurso de "guerra contra las drogas" proyectado desde los Estados Unidos desde los años ochenta, se han promulgado leyes represivas que no respetan el principio de proporcionalidad, incidiendo en los eslabones más bajos de las organizaciones criminales. Esta política criminal en sintonía con la tolerancia cero de la criminalidad callejera supone la represión dura frente al microtráfico, olvidando la gran criminalidad del narcotráfico que, en muchos casos está emparentada con la corrupción política. Se trata de propuestas de "duros contra los débiles y débiles contra los duros" que, finalmente es expresión de la gran Política Criminal punitivista, simbólica, excesiva y de doble moral, que domina nuestro tiempo con un marcado acento en el mantenimiento del status quo y del encarcelamiento de los sectores marginados de la Sociedad (Paladines, 2015: 13).

Es también una Política Criminal en línea con una mayor tolerancia hacia la delincuencia de cuello blanco que, además, posee mayor cantidad de dinero para una defensa más eficaz, está bien situada social y económicamente, y cuenta con los prejuicios sociales atávicos de la opinión pública de asociar la delincuencia con delitos de sangre, violentos, con víctimas observables empíricamente. Como ya se ha dicho, en estos supuestos del tráfico de drogas, las víctimas no son realmente víctimas en la mayoría de los casos, sino sujetos cooperadores con el delito que consensuan en un mercado ilícito la compra de un bien deseado. En muchos casos, los agentes del tráfico de drogas situados en las altas esferas de la cadena de producción ilegal cuentan también con la connivencia de los aparatos del Estado, vía corrupción, pagos de sobornos para que por acción u omisión las fuerzas del orden, los jueces o fiscales se retraigan en la persecución penal.

Por tanto, se constata una gran desigualdad en la persecución penal dentro del tráfico ilícito de drogas. ${ }^{3}$ Por un lado, un punitivismo contra el microtráfico y los agricultores de la hoja de coca y, por otro, impunidad para los grandes narcotraficantes; lo cual permite dar curso a esa doble moral que caracteriza la persecución penal del tráfico de drogas:

\footnotetext{
${ }^{3}$ Como constata Torrente (2001: 13): "El delito es una forma de desigualdad que se suma a otras. Víctimas y delincuentes no se distribuyen de forma aleatoria entre la población. Se concentran en las personas que ya padecen otras formas de discriminación". Si esto es así con carácter general, en el caso de la persecución del delito de tráfico de drogas esta desigualdad es aún más acuciante.
} 
simbólicamente se pueden dar cifras de eficiencia penal con los datos de incautaciones y sujetos encarcelados por drogas, por otro lado, los grandes capos de las mafias del narcotráfico mantienen el negocio ilícito de drogas para sus consumidores y los sujetos integrados en la cadena de valor del mercado ilegal.

Como es difícil cuantificar la incidencia del tráfico de drogas en un país, resulta muy fácil mostrar a la opinión pública cifras de "éxitos" sobre lucha contra las drogas, con detenciones, incautaciones y estadísticas de encarcelamiento que poco inciden en su real prevención. Como sostiene Peláez (2014: 47): “es imposible saber cuántos delitos de tráfico de drogas se comete porque simplemente no se denuncian y tampoco se detectan. Para contabilizar la incidencia del tráfico de drogas, se emplean otros datos, como por ejemplo el número de personas detenidas a las que se le imputa el delito de tráfico, y eso siempre ocurre a posteriori, una vez detenido el delincuente". Tampoco los países suelen contabilizar las tasas de delitos cometidos por organizaciones criminales, sino simplemente las estadísticas suelen realizarse por los delitos emblemáticos de tráfico de drogas, trata de personas, blanqueo de capitales, etc.

\section{EL FENÓMENO DE LA CORRUPCIÓN (DEL NARCOTRÁFICO) EN EL PERÚ}

Por supuesto que no cabe en este trabajo desarrollar las complejas relaciones sociales y económicas que genera la corrupción en el Perú, pues sus raíces pueden encontrarse desde la Colonia, por tanto, incluso antes del nacimiento de la República. Como anota el gran estudio sobre la corrupción peruana de Quiroz (2013: 29), "Varias generaciones de redes corruptas adeptas a la violación endémica de reglas establecidas, así como sus afines interconexiones internacionales, surgen como factores que ligan las prácticas corruptas en las esferas pública y privada". Por tanto, el narcotráfico no puede considerarse causa o efecto de la corrupción, pues confluyen una serie de variables sistémicas del país, pero sí puede decirse que se trata de un ingrediente importante.

Las vinculaciones del narcotráfico con la corrupción de las altas esferas del Estado ha sido una constante en el Perú, pues desde que el fenómeno del tráfico de drogas internacional empezó a desarrollarse con fuerza, esto es desde los años ochenta, ha debido de contar con la colaboración de algunos miembros de las fuerzas del orden para asegurar la producción, comercialización del clorhidrato de cocaína y su exportación a los mercados internacionales. Y, en el caso de ser procesados los autores, no han faltado jueces y fiscales que han asegurado la impunidad de los grandes narcotraficantes.

El fenómeno del terrorismo que se desarrolla en los años ochenta precisamente con más fuerza en las zonas donde se cultiva la hoja de coca, que expresa también alianzas estratégicas entre narcotráfico y guerrilla, va a ser un buen pretexto para que las fuerzas del orden neutralicen el compromiso del gobierno con la erradicación de la coca y la interdicción del tráfico de cocaína. Un informe de septiembre de 1989 de la Agencia de Inteligencia de Defensa de los Estados Unidos afirmaba que "los militares peruanos están ahora involucrados con los traficantes de drogas al tiempo que intentan erradicar la insurgencia" (Quiroz, 2013: 347).

Pero el culmen de esta alianza de militares con el narcotráfico llega con el Gobierno Fujimori-Montesinos. Sabedores del impacto económico y sociopolítico del tráfico de drogas en el país, una estrategia fundamental de ese gobierno fue el dominio militar de la política antidroga y su ejecución. En 1990 Fujimori reorganizó el Ministerio del Interior en un afán por centralizar el control militar tanto de los operativos antinarcóticos como antiterroristas, a la par que minaban los tribunales especiales que procesaban los delitos 
relacionados con drogas, reemplazándolos por tribunales ordinarios presididos por jueces y fiscales patrocinados por Montesinos. Un mayor control por parte de los militares y los servicios de inteligencia que lideraba Montesinos estaba justificado para prevenir la alianza de los narcotraficantes con los terroristas en algunas zonas del país.

Como recuerda Quiroz (2013: 410), "la participación pasada de Montesinos en la defensa legal de narcotraficantes y en el suministro de información a la CIA, tuvo un papel crucial en sentar las bases del perverso sistema antidrogas que quedó firmemente asentado después del golpe de 1992”. Por Decretos ejecutivos el ejército tomó el mando exclusivo de las operaciones antidrogas en regiones claves, además del control de los aeropuertos y puertos marítimos. Se instaló un sistema que daba curso a la doble moral de la persecución del narcotráfico, "por un lado, Montesinos contaba con el necesario respaldo local e internacional para asumir el control de las operaciones de interdicción de las drogas, que bajo su mando fueron consideradas "efectivas" por los especialistas. Por otro lado, el aparato militar-SIN (Servicio de Inteligencia) permitía las actividades de narcotraficantes, pero, al mismo tiempo, ordeñando para beneficio propio los ingresos derivados de estas" (Quiroz, 2013: 411) ${ }^{4}$.

El dinero proveniente del narcotráfico fue, conjuntamente con otros ingresos dinerarios como las privatizaciones, los porcentajes de comisiones de compras de armas, desvió de fondos antidrogas desde los Estados Unidos, etc., el lubricante para financiar el tráfico de influencias y los sobornos para comprar todas las instituciones centrales del país, en la década infame del gobierno Fujimori-Montesinos de los años noventa. Se trata de la mayor captura del Estado por parte de la corrupción política de la historia del Perú. Los tentáculos del aparato Fujimori-Montesinos se propagaron por los altos mandos militares, policiales, Fiscalía, Poder Judicial, el Congreso, los medios de comunicación, los empresarios más poderosos. La cleptocracia se instaló en el país por todas las esferas más altas del poder económico y político, con redes clientelares dominadas desde la cúpula del gobierno, con un costo inconmensurable para el desarrollo de la sociedad civil y el progreso de los más desfavorecidos (Lamas, 2019) ${ }^{5}$.

\section{LA (PEN)ÚLTIMA CAPTURA DEL ESTADO: EL CASO “CUELLOS BLANCOS DEL PUERTO”}

\footnotetext{
${ }^{4}$ A comienzos de la década de 1990, Demetrio Chávez Peñaherrera, alias "Vaticano", operaba desde una pista de aterrizaje en Campanilla, región del Alto Huallaga, como proveedor de pasta básica de cocaína a los cárteles colombianos. Sus operaciones comprendieron 280 vuelos de aviones ligeros entre Perú y Colombia entre 1991-1993. Vaticano declaró en su juicio haberle entregado 50000 dólares mensuales a Montesinos y a los comandantes de la zona militar para que ignoraran los vuelos. Se negó a pagar cuando la cuota fue elevada a 100000 dólares mensuales y entonces huyó a Colombia. En enero de 1994 Vaticano fue arrestado en Bogotá y extraditado al Perú, donde se le acusó de colaborar con terroristas y se le tuvo aislado, sometido a torturas en una prisión militar. El caso fue transferido a un tribunal civil ante las evidencias de falta de conexiones con hechos terroristas. En este juicio Vaticano declaró haber sobornado a Montesinos y a las autoridades militares y que ocasionalmente recibía mensajes radiales advirtiéndole de las inminentes incursiones antidrogas (Quiroz, 2013: 411).

${ }^{5}$ Siguiendo a Rehren (2000: 137): "la corrupción tiene entre sus características que inhibe la formación de grupos autónomos en la sociedad civil, creándose poderosos vínculos de dependencia y de explotación en las grandes mayorías por parte de grupos, aunque minoritarios, lo suficientemente poderosos y corruptos. Se reduce la política y la discusión de temas de interés público a un ámbito de intereses facciosos, deslegitimando el proceso formal, el rol de los partidos y las instituciones políticas. En este contexto, la permeabilidad de la clase política a la corrupción tiene un impacto desintegrador para la sociedad en su conjunto. Además, las consecuencias económicas de la corrupción tienden a minar las bases económicas que sustentan una democracia liberal".
} 
Precisamente las escuchas telefónicas decretadas judicialmente para la investigación de una banda de narcotraficantes que se sospechaba actuaban en el puerto de El Callao, destapó el contubernio de las autoridades judiciales de la provincia y, poco a poco, se fue desmadejando una gran trama de corrupción judicial y política de alto nivel. El proceso judicial abierto a estos magistrados se denominó "los cuellos blancos del puerto".

Como antecedente para el lector, debe señalarse que el puerto de El Callao, situado en la mitad del continente suramericano a orillas del Pacífico, es el puerto más importante en volumen de carga del continente americano. Aunado a esto, el Perú es el segundo exportador del mundo de cocaína y últimamente las rutas de comercialización de este producto se realizan fundamentalmente por vía marítima. Ergo, es fácil colegir que desde este puerto salen al extranjero toneladas de cocaína ${ }^{6}$. Las exportaciones vía contenedores, es decir, grandes cubículos en los que se introduce diversos productos, facilita que, dentro de ellos, o precintados para introducir en algún lugar de la ruta, se envíen sustancias ilegales. Por supuesto que no se pueden revisar todos los contenedores y ello lo saben los narcotraficantes. Basta con que algún aduanero no revise algún contenedor en concreto para que la cocaína salga del país. La proliferación del crimen organizado en el lugar no es algo sorprendente. En 2015, al menos 21 personas fueron asesinadas a manos de sicarios, normalmente jóvenes. La violencia entre bandas criminales se desató creando gran alarma social entre la población limeña ${ }^{7}$. Cabe señalar que, en Perú, a diferencia del caso colombiano, el uso de la violencia no es una constante por lo que inmediatamente saltan a la luz cuando aumentan los índices de violencia. Como señala Cubides (2014: 684) "en el caso de Perú, este no manifestó niveles altos de violencia relacionados con el narcotráfico puesto que participa únicamente en el cultivo y la producción de la cocaína, dimensiones que en sí mismas no implican la aplicación de violencia. Sin embargo, una observación regional evidenció que, si bien el cultivo no es condición de presencia de altas tasas de homicidio, si a esta se le suman variables como la presencia de áreas estratégicas y áreas en disputa, pueden manifestar niveles de violencia altos. Esto explica que, aunque la tasa nacional no llegue a los niveles colombianos, habrá algunas regiones del país que tengan tasas de homicidio superiores a la tasa nacional". Ciertamente el puerto de El Callao se convirtió en un puesto estratégico para la exportación de la cocaína, desarrollando niveles de violencia nunca antes vistos.

Las interceptaciones telefónicas investigando múltiples delitos del crimen organizado en esa zona desvelaron que el entonces Presidente de la Corte Superior del Callao, un Magistrado de la Corte Suprema ${ }^{8}$, ex Consejeros del Consejo General del Poder Judicial (órgano judicial encargado de la selección y promoción de los jueces), favorecían con sus resoluciones casos de narcotráfico, entre otros. Estas escuchas mostraron las vinculaciones de la criminalidad organizada con diversos estamentos judiciales y políticos del país. Cual redes clientelares, los fenómenos de la criminalidad organizada se entrecruzan con la corrupción de la Administración del Estado asegurando la impunidad de aquella y perpetuando el negocio ilícito del narcotráfico, para beneficio de altos funcionarios inescrupulosos capaces de poner precio a sus servicios en beneficio personal. Se presenta, así, la intersección entre las organizaciones criminales del narcotráfico con las organizaciones de la corrupción pública (IDEHPUCP, 2019). El asunto sigue en proceso de juzgamiento, pues se ha ido descubriendo a lo largo de la investigación los nexos con otros funcionarios de la Corte Suprema, la Fiscalía de la

\footnotetext{
${ }^{6}$ Aunque existen otros puertos, como el de Paita al sur del país y Moyendo en el norte, lo cierto es que desde el puerto de El Callao se realizan las principales exportaciones del país.

${ }^{7}$ Vid. el Reportaje del Programa de TV Panorama (Panorama, 2015).

${ }^{8}$ Prófugo de la justicia y con orden de extradición desde España.
} 
Nación, empresarios, miembros del Congreso de la República, lo cual demuestra el calado de la corrupción en el país. Hechos, por tanto, que se han desarrollado a lo largo de varios años, por medio de redes clientelares a favor del beneficio ilícito personal, en desmedro de las funciones públicas.

Lo cierto es que se trata del caso más grave de corrupción judicial en el país, pero no es el único. Como se señala Ojo Público (2020a) "es solo la punta del iceberg de las redes ilícitas infiltradas en las instituciones encargadas de investigar el delito. La semana pasada, la Procuraduría Pública Especializada en Delitos de Corrupción (PPEDC) difundió el estudio denominado "Corrupción en el sistema de justicia: Caso Los Cuellos Blancos del Puerto", el cual señala que un total de 334 magistrados (151 jueces y 183 fiscales) están involucrados o sentenciados por presuntos actos de corrupción en todo el país". Por tanto, no se trata de un caso aislado, sino de un fenómeno bastante generalizado ${ }^{9}$, lamentablemente, en el sistema judicial del país.

Lo grave en el asunto "cuello blanco del puerto" es la captura por parte del narcotráfico de personalidades emblemáticas, como es el caso del Presidente de la Corte Superior del Callao (máximo órgano de la Provincia) y de al menos un Magistrado de la Corte Suprema, muy vinculado con varios magistrados de instancias inferiores (a los que llamaba "hermanitos", según los audios,), incluso presuntamente Fiscales Supremos que están siendo investigados con grandes dificultades dada su condición de aforados. Se trata pues, de que el narcotráfico en el Perú logró obtener la colaboración de funcionarios del Estado en las más altas esferas judiciales para asegurarse la impunidad. Nuevamente, una expresión del entrecruce de las redes del crimen organizado con las redes de la corrupción judicial. Se trata de, al menos, dos organizaciones criminales que tienen nodos comunes, que colaboran entre ellas con una finalidad común: el lucro ilícito. Evidentemente, el daño al Estado peruano y a la sociedad civil es inconmensurable, en la confianza de los ciudadanos, en el grado de democratización del país, en el sistema financiero, en las expectativas en la justicia. En un país con grandes desigualdades sociales, con problemas de cohesión social, la corrupción judicial ahonda las brechas sociales y la fiabilidad de los ciudadanos -especialmente de los más vulnerables- en el respeto de sus derechos fundamentales.

\section{CORRUPCIÓN JUDICIAL Y NARCOTRÁFICO EN EL PERÚ}

Como ha podido verse, el caso "cuellos blanco del puerto" es solo un síntoma de un problema más profundo: la corrupción sistémica en el país andino. El estudio profundo del historiador Quiroz (2013) muestra innumerables etapas de la historia peruana protagonizadas por el aprovechamiento de las estructuras estatales para el enriquecimiento ilícito propio. El caso Odebrecht en los últimos años desató un terremoto político, mostrando también cómo las autoridades que dirigen el país (presidentes, expresidentes) o pretenden dirigir el país (candidatos a la presidencia), empresarios con prestigio económico y social, se dejaban sobornar por la empresa brasileña para obtener

\footnotetext{
${ }^{9}$ Continuamente se dan a la luz por los medios casos de jueces y fiscales comprados por el narcotráfico. Solo como ejemplo, "Juez prohibió a la Fiscalía y a la DIRANDRO que sigan investigando a "ETECO" por narcotráfico” (Ojo Público, 2020b). En fallo judicial inédito en el Perú, el juez Mariano Méndez de Tarapoto falló a favor de Hábeas Corpus interpuesto por Miguel Arévalo, sindicado por la Fiscalía y la Dirandro como cabecilla de una organización criminal dedicada al tráfico de drogas. Juez advirtió al fiscal Álvaro Rodas y al jefe del grupo de inteligencia Orión, coronel PNP Walter Lozano, que lideran el caso desde el 2018, de ser denunciados, bajo "responsabilidad funcional”, en caso sigan investigando a 'Eteco' (Miguel Arévalo). Cabe señalar que Tarapoto es una zona de selva en la que se desarrolla el narcotráfico.
} 
contratos públicos millonarios ${ }^{10}$. La corrupción, por tanto, lamentablemente, es una constante en los procesos sociales del país.

Pero el problema es mayúsculo cuando son los aparatos encargados de hacer cumplir la ley los que trabajan del lado de los delincuentes, para enriquecerse personalmente. El daño al Estado de Derecho, a la Democracia, es tremendo porque a los ciudadanos se les conculca su derecho fundamental a la tutela judicial efectiva, principal monopolio del Estado, lo cual alimenta la anomia, precisamente caldo de cultivo del crimen organizado. Se produce, así, un círculo vicioso difícil de contrarrestar, que puede ir creciendo como una gran bola de nieve, llegando un momento en que es muy complicado hacer frente a organizaciones criminales poderosas, porque se han infiltrado en los aparatos del Estado, siendo capaces de amenazar la seguridad nacional, como sucede lamentablemente en México ${ }^{11}$.

De ahí que la Política Criminal moderna se preocupe de los llamados "colaboradores" con el crimen organizado. Un estudio realizado en España sobre los perfiles criminales en la delincuencia organizada española señaló que casi un $60 \%$ de los sujetos imputados por delitos de la criminalidad organizada mantienen su actividad legal en paralelo a su actividad delictiva (Giménez-Salinas, 2011: 28). Esto nos muestra que el mundo del crimen organizado no sólo está compuesto por profesionales del delito, es decir criminales dedicados organizadamente a la realización de delitos, sino también por colaboradores de distintas profesiones que dan soporte de todo tipo a las organizaciones criminales. Esta información resulta relevante para inducir que existen muchas personas que se encuentran en la periferia de las organizaciones criminales, no integran las mismas, pero son las que las alimentan, asesoran y hasta aseguran la impunidad.

Se trata de un ejército de policías, militares, jueces, fiscales, abogados, aduaneros, empresarios, políticos, asesores, que están al servicio de las organizaciones criminales, por supuesto no a tiempo completo como miembros de las mismas, pero que al realizar sus colaboraciones dentro del ejercicio de sus actividades profesiones, no levantan ninguna sospecha, por lo cual resulta muy difícil desenmascarar. Nos encontramos ante los delitos de cuello blanco que se realizan en contextos normalizados (Zúñiga, 2018) y que pueden actuar impunemente porque les protege la inmunidad de su actuación dentro de actividades inocuas, socialmente admitidas, incluso respetadas.

Nuevamente el juego de la doble moral hace su aparición. Se trata de sujetos que aparentan cumplir con las reglas del ejercicio de su profesión, pero por detrás de las cortinas realizan importantes colaboraciones con el crimen organizado. Colaboraciones tan importantes, que a veces son más relevantes que las propias de las actividades de los miembros de las organizaciones criminales. No por menos ha de valorarse una sentencia a favor de la comisión delictiva, un habeas corpus que pone en libertad un narcotraficante,

\footnotetext{
${ }^{10}$ Sintomático es el hecho de que Alejandro Barata, el intermediario en el caso Odebrecht revelara que él no corrompió a las autoridades peruanas, éstas ya estaban corruptas, demostrando la facilidad con la que este señor podía sobornar a dichas autoridades.

${ }^{11}$ Las sucesivas fugas del Chapo Guzmán, los sonados casos de corrupción de militares, jueces, y hasta del expresidiente Peña Nieto muestran una tremenda infiltración de la criminalidad organizada en los más altos estratos del Estado mexicano. La siguiente noticia es expresión de esas colusiones: (Reina, 2020), "Detenido en Estados Unidos el jefe del ejército mexicano del gobierno de Enrique Peña Nieto": "Estados Unidos ha sacudido México con la detención del que fuera el jefe máximo del Ejército mexicano durante el Gobierno de Enrique Peña Nieto, de 2012 a 2018. El general Salvador Cienfuegos fue arrestado el jueves por la noche en el aeropuerto de Los Ángeles a petición de la Agencia de Drogas Estadounidense (DEA), mientras viajaba con su familia".
} 
los indultos en favor de procesados por narcotráfico ${ }^{12}$, el asesoramiento para el blanqueo de dinero, etc., etc. Pueden ser innumerables los casos que se inscriben en esta línea. En el ámbito judicial desde "pequeñas ayudas" como diferir la investigación por parte del fiscal o el juez, como "grandes ayudas" como poner en libertad al narco o asegurarle una sentencia absolutoria o de menor pena. Todo tiene un precio diferenciado, por supuesto. Y, en muchos casos, los abogados defensores son los intermediarios.

Grandes preguntas se plantean ante esta realidad criminológica. ¿El narcotráfico y el crimen organizado tienen un efecto corruptor en las estructuras judiciales o las organizaciones criminales encuentran un hábitat de corrupción que favorece esta colusión?

No existen aún profundos estudios criminológicos al respecto para dar respuestas ciertas a esa interrogante, pero lo cierto es que queda claro que en el país existen importantes alianzas entre el crimen organizado y la corrupción judicial de las más altas estructuras del Estado. Sino no se explica el exitoso desarrollo del negocio ilícito del narcotráfico, trajinado por la doble moral de persecución penal dura para los débiles y débil para los fuertes.

También resulta una evidencia que el crimen organizado encuentra en el país andino unas coordenadas sociales propicias para su desarrollo que es la Gran Corrupción. Como apuntan Ugaz y Hava (2016: 281), en todos los países se presentan rasgos de corrupción a diferentes niveles de la Administración Pública. El problema se presenta cuando se trata de la Gran Corrupción: "actos cometidos en los niveles más altos del gobierno que involucran la distorsión de políticas o de funciones centrales del Estado, y que permiten a los líderes beneficiarse a expensas del bien común". Sin duda la distorsión de la labor de la Administración de Justicia en las más altas esferas del Estado para favorecer a los narcotraficantes, se inscribe dentro de esta definición de Gran Corrupción.

Por tanto, las alianzas entre el crimen organizado y la corrupción política, especialmente la judicial, se inscriben en un contexto de Gran Corrupción, donde los factores económico, político, sistémico, social, impunidad se conjugan para fortalecer las redes criminales del narcotráfico y del enriquecimiento ilícito de la administración de justicia, traducida en esa doble moral de que se persigue la criminalidad organizada pero no efectivamente, o, al menos, no contra los grandes capos de la droga, normalmente protagonistas del tráfico internacional de drogas.

Las grandes cifras de la informalidad de la economía peruana facilitan el reciclaje del dinero de procedencia ilícita, pues puede circular libremente en ese mercado paralelo. Otro índice relevante es la cantidad de fallos del sistema judicial para perseguir este el blanqueo de capitales. Los mayores registros de fondos ilícitos involucrados en los reportes de la Unidad de Inteligencia Financiera del Perú (UIF) provienen del tráfico de

\footnotetext{
${ }^{12}$ El caso de los "narcoindultos" en el segundo mandato del gobierno de Alan García es su mayor expresión. Miguel Facundo Chinguel, fue presidente de la Comisión de Gracias Presidencial y durante su presidencia se indultaron a numerosos sujetos procesados por narcotráfico. El asunto se dio a conocer el 31 de marzo del 2013. Un informe del programa de TV "Cuarto Poder" se basó en una investigación que llevaba a cabo la denominada megacomisión que investigó las presuntas irregularidades del segundo gobierno de Alan García. En diciembre de 2015 Miguel Facundo Chinguel fue sentenciado tras ser hallado responsable de montar una organización delictiva al interior de la comisión que lideró del 2008 al 2010. Esta, según la fiscalía, cobraba sobornos a los internos a cambio de reducir sus penas, pese a que no cumplían con los requisitos para ese beneficio. No se pudo probar las vinculaciones con el Ministro de Justicia y el Presidente de la República que firmaban los indultos, pero se sospecha de la participación de los mismos en estos actos de corrupción (El Comercio, 2016).
} 
drogas (Prado, 2016: 379). Este mismo autor denuncia la timidez en la prevención y control del blanqueo, sino malas prácticas o indecisiones observadas en el tratamiento penal de los casos judicializables o judicializados, los cuales marcan una preocupante proyección hacia la impunidad. Queda claro que en un país donde no se persigue idóneamente el blanqueo de capitales proveniente del narcotráfico, encuentran sus autores terreno abonado para perpetrar sus prácticas ilícitas. No sólo no existen desincentivos, sino más bien existen incentivos para proseguir ampliando el mercado de drogas ilícitas. Las ingentes cantidades de dinero proveniente del narcotráfico es una herramienta corruptora de primer calibre que ha mostrado históricamente su capacidad para capturar las altas esferas de los poderes del Estado: Ejecutivo, Legislativo y Judicial.

El último Informe de GAFILAT (2019: 12), reconoce los avances el país en mejorar el aparato jurídico, pero considera que, pese a la existencia de investigaciones, procesos y condenas por lavado de activos, "los resultados no son congruentes en magnitud con respecto al nivel de riesgo al que está expuesto el Perú. La mayoría de las condenas por lavado de activos están relacionadas con el delito determinante de tráfico ilícito de drogas y en menor grado con otros. Se identifican los casos de lavado de activos para investigación, pero no resulta evidente que en las investigaciones de casos complejos se esté persiguiendo la recuperación de activos y desarticulación financiera de las redes criminales, en la generalidad de los casos".

\section{UN MARCO MÁS AMPLIO: DELITO DE LAS ORGANIZACIONES}

La prevención del narcotráfico y el blanqueo de capitales para ser eficaz ha de enmarcarse en un ámbito más amplio que es una Política Criminal contra la corrupción y el crimen organizado de cuello blanco. Se trata de analizar estas redes delincuenciales que se entrecruzan, colaboran y establecen alianzas, encontrando en el Perú en el núcleo el dinero proveniente del narcotráfico. En el trasfondo encontramos los denominados por los criminólogos delito de organizaciones (Torrente, 2001: 83-84). Efectivamente, la sociedad suele tolerar estas formas delincuenciales que discurren en el ejercicio de la profesión por la poca visibilidad que despiertan y porque no se trata de una confrontación directa con las normas sociales (doble moral, o al menos, delitos ambiguos). La filosofía de estos delincuentes profesionales tiene un sesgo cognitivo que les alienta ("todo el mundo es deshonesto", "todo el mundo es corrupto", "cada persona tiene un precio") y cuentan con una sociedad que va en línea con el reconocimiento social - y hasta la adulación- de quien más dinero tiene sin importar cómo lo ha obtenido. Además, se trata de delitos complejos, con víctimas invisibles o colaboradoras con el autor, que se desarrollan en contextos normalizados (negocios legales), a lo largo del tiempo, con una diversidad de intervinientes, difíciles de identificar y, por tanto, detectar, perseguir y castigar. Los procesos suelen ser largos, complicados, con muchos procesados, engorrosos por la multiplicidad de pruebas y escritos que se presentan. Su dinero les permite tener los mejores abogados defensores. Todo esto lo saben los delincuentes de cuello blanco y cuentan con ello, apoyados por sus amigos de las redes clientelares.

No puede olvidarse que el narcotráfico provee de trabajo, bienes y servicios a ciertos sectores de la población al que el Estado peruano no suele llegar. Por tanto, suele existir muchas personas necesitadas que viven del mercado del narcotráfico. Son los que están en los puestos más bajos de las organizaciones y pueden aparecer socialmente como delincuentes. Pero los que se sitúan en los escalones más altos con frecuencia alternan con las élites de la sociedad no delincuente y, por tanto, no son etiquetados como desviados sociales. A vueltas con la doble moral. 
Si el Derecho Penal es eminentemente selectivo, en la persecución penal del narcotráfico y la corrupción que genera esta selectividad se vuelve más evidente. Punitivismo para los débiles y mano suave para los poderosos, en un juego de simbolismos que es preciso desenmascarar, analizar y conjurar. Así, las autoridades siempre tendrán cifras de operaciones exitosas, incautaciones que ofrecer públicamente, mientras en la realidad criminológica siguen discurriendo relaciones sistémicas de cultivo, producción y comercialización de cocaína, con la que se benefician algunos de las altas esferas de la sociedad.

¿Cómo desarticular estas redes del narcotráfico y el mercado ilegal que generan? Obviamente las respuestas son de largo alcance y sobrepasan los límites de este trabajo porque sin duda se deben combinar la prevención y la represión, lo cual merecería una Política Criminal integral que aborde los diversos factores coadyuvantes. Los estudiosos barajan la discusión sobre la despenalización del tráfico de drogas, pues la legalización traería consigo acabar, al menos, con la corrupción y la violencia que genera la comercialización de sustancias estupefacientes, como sucedió en su día con la venta de alcohol. Otros abogan por una "prohibición flexible", como Díaz (2017: 402). Siguiendo a Valle define esta tipología, como aquella en la que "convive un derecho penal máximo para el caso de producción y distribución mayorista de drogas, con un derecho penal mínimo, para el caso de consumo y distribución minorista". Todo lo contrario de lo que sucede en la actual realidad penológica que, como hemos dicho, se caracteriza por ser fuerte para los débiles y débil para los fuertes.

Con esta propuesta al menos se daría un paso para desenmascarar la doble moral que se ha instalado en la Política Criminal contra las drogas y, neutralizaría algo -al menoslas alianzas entre las élites y el narcotráfico, rebajando su capacidad para infiltrarse y capturar los poderes del Estado. Poner el acento en la persecución penal de los narcotraficantes de cuello blanco y sus colaboradores (que, como se ha dicho, a veces realizan aportaciones más importantes que los propios miembros de la organización) es una importante arista de esta problemática sin fin.

NOTA SOBRE LA AUTORA:

Laura Zúñiga Rodríguez es Catedrática de Derecho Penal en la Universidad de Salamanca, España. Correo electrónico: 1zr@usal.es

\section{REFERENCIAS}

AMERIPOL (2013), Análisis situacional del narcotráfico. Una perspectiva policial. Bolivia, Brasil, Colombia, Ecuador, Panamá y Perú, Bogotá: FIIAPP. http://www.ameripol.org/portalAmeripol/appmanager/portal/desk?_nfpb=true\&_pageLa bel=portals_portal_page_m2p1p2\&content_id=48019

Armao, Fabio (2014), "Criminal Clusters: State and Organised Crime in a Globalised World”, The European Review of Organised Crime, Vol. 1, No. 1, pp. 1-44.

Chabat, Jorge (2010), "El Estado y el crimen organizado transnacional: amenaza global, respuestas nacionales", Revista de Historia Internacional, Vol. 11, No. 42, pp. 3-14. http://200.92.215.37/images/electronicos/Seguridad/ELeSTADOyELcRIMENoRGANI ZADOtRANSNACIONAL.pdf 
Cubiedes Salazar, Olga M. (2014), "La violencia del narcotráfico en los países de mayor producción de coca: los casos de Perú y Colombia”, Papel Político, Vol. 19, No. 2, pp. 657-690. http://www.scielo.org.co/pdf/papel/v19n2/v19n2a11.pdf

Díaz Cortés, Lina M. (2017), "Las razones de la legitimidad de las políticas criminales frente a las drogas ilícitas: Análisis a partir de los modelos de control jurídico (I)”, en Zúñiga Rodríguez, Laura (Dir.), Criminalidad organizada transnacional: una amenaza a la seguridad de los Estados democráticos, Valencia: Tirant lo Blanch, pp. 377-419.

El Comercio (2016), "Miguel Facundo Chinguel: las 7 claves del caso narcoindultos", 16 de agosto. https://elcomercio.pe/politica/justicia/miguel-facundo-chinguel-7-clavescaso-narcoindultos-398312-noticia/?ref=ecr

GAFILAT (2019), "Informe de Evaluación Mutua del Perú". http://www.fatfgafi.org/media/fatf/documents/reports/mer-fsrb/GAFILAT-Mutual-Evaluation-Peru2019-Spanish.pdf

Giménez-Salinas, Framis A. (2011), “Existe un perfil de delincuente organizado? Exploración a partir de una muestra española”, Revista Electrónica de Ciencia Penal y Criminología, Vol. 13, No. 3, pp. 1-32. http://criminet.ugr.es/recpc/13/recpc13-03.pdf

IDEHPUCP (2018), "Lavado de activos en cooperativas de la región de Ayacucho provenientes del tráfico ilícito de drogas y su inserción al mercado legal". https://cdn01.pucp.education/idehpucp/wp-content/uploads/2018/11/14171043/3lavado-de-activos-en-cooperativas_proyectoanticorrupcion-idehpucp.pdf

- (2019), "Casos emblemáticos: CNM audios (caso cuellos blancos del puerto". https://cdn01.pucp.education/idehpucp/wpcontent/uploads/2019/03/27203910/R EPORTE-CUELLOS-BLANCOS.-pdf

Lamas Puccio, Luis (2019), Corrupción, cleptocracia y globalización, Lima: LP Abogados.

Manrique López, Hernán (2015), "Política de drogas y narcotráfico en el Perú: del triunfalismo peruano al laberinto de la cocaína", Revista Cultura y droga, Vol. 20, No. 22, pp. 64-85.

Noticias ONU (2020), "Récords de cultivo de hoja de coca, nuevos cárteles y aumento de la violencia: la droga en América Latina", 27 de febrero. https://news.un.org/es/story/2020/02/1470231

Ojo Público (2020a), "Enemigo en casa: los jueces y fiscales corruptos que coparon el sistema judicial en el Perú", 6 de mayo. https://ojo-publico.com/1809/el-enemigo-encasa-magistrados-corruptos-en-el-sistema-de-justicia

- (2020b), "Juez prohibió a la Fiscalía y a la DIRANDRO que sigan investigando a "ETECO" por narcotráfico", 27 de octubre. https://ojo-publico.com/2199/juezprohibio-la-fiscalia-y-la-dirandro-que-investiguen-eteco

Paladines Rodríguez, Jorge V. (2015), “Duros contra los débiles y débiles contra los duros'. La lección no aprendida", Rebelión. www.rebelion.org/docs/204138.pdf

Panorama (2015), "Violencia en el Callao: ganancias con muerte", 22 de febrero. Vídeo de Youtube, 15:03. https://www.youtube.com/watch?v=EXp_bMTRSgY

Peláez Piñeiro, Luis (2014), Estrategias de respuesta de la Guardia Civil en materia de delincuencia grave y organizada, Trabajo de Fin de Máster. Universidad Internacional Menéndez Pelayo. 
Piedrahita Bustamante, Pedro (2020), "Local y global: el Estado frente al delito transnacional", Revista Derecho del Estado, No. 46, pp. 137-160. https://revistas.uexternado.edu.co/index.php/derest/article/view/6503/8850

Prado Saldarriaga, Víctor (2016), "Criminalidad organizada y lavado de activos en el Perú”, en Zúñiga Rodríguez, Laura (Dir.), Ley contra el crimen organizado (Ley $N^{o}$ 30077). Aspectos sustantivos, procesales y de ejecución penal, Lima: Instituto Pacífico, pp. 355-385.

Quiroz, Alfonso (2013), Historia de la corrupción en el Perú, Lima: Instituto de Estudios Peruanos.

Rehren, Alfredo (2000), "Clientelismo político, corrupción y reforma del Estado", documento de trabajo No. 305, Santiago de Chile, Centro de Estudios Públicos. https://www.cepchile.cl/cep/site/artic/20160304/asocfile/20160304093611/refor2_02_re hren.pdf

Reina, Elena (2020), "Detenido en EE UU el jefe del Ejército mexicano del Gobierno de Enrique Peña Nieto", 16 de octubre. https://elpais.com/mexico/2020-10-16/detenido-enee-uu-el-ex-secretario-de-la-defensa-con-enrique-pena-nieto.html

Soberón, Ricardo (2010), "Legislación en materia de drogas y situación carcelaria en el Perú", Transnational Institute (TNI). http://druglawreform.info/es/informacion-porpais/america-latina/peru/item/251-peru

Stöckil, Gabriela (2014), "El narcotráfico en el Perú: ¿Lucha contextualizado o contexto en lucha?", Revista de la Pontificia Universidad Católica del Perú, No. 7, pp-8-17.

Torrente, Diego (2001), Desviación y delito, Madrid: Alianza Editorial.

UNODC (2020) «Efectos del Covid en los mercados de las drogas". https://wdr.unodc.org/wdr2020/field/V2002977_ExSum_Spanish.pdf

Ugaz, José y Hava, Esther (2016), “Cómo definir la Gran Corrupción”, en Zúñiga Rodríguez, Laura (Dir.), Ley contra el crimen organizado (Ley $N^{o}$ 30077). Aspectos sustantivos, procesales y de ejecución penal, Lima: Instituto Pacífico, pp. 275-297.

Zúñiga Rodríguez, Laura (2018), "Corrupción y la categoría "delito de cuello blanco": cuando los delitos se cometen en contextos normalizados", Ius et Veritas, No. 57, pp. 162-169. 